\title{
To abrupt change
}

\section{Early warning of the Earth's tipping points will bring us closer to staving off abrupt climate change, but a societal tipping point is needed to achieve sustainability.}

Almost 20 years have now passed since world leaders officially recognized the need to urgently address the ongoing overexploitation of the Earth's resources. Despite the 1992 Rio Earth summit's pledges to protect the environment, we have continued on a trajectory of unrestrained growth, pushing our planet's key physical and biological systems to the limits of their ability to cope with change. We have, so far, been fortunate in that the Earth's capacity for self-regulation has protected us from the reality that, at some point, we will probably push it too far, into a state unlike the one we now enjoy.

Already, our very existence - which has thrived under the relative stability of the Holocene over the past 11,700 years is having an impact that will be great enough, it seems, to leave an indelible mark in the geological record. Indeed, geologists are making the case for official recognition of the 'Anthropocene' as an epoch where human activities, such as fossil fuel combustion and deforestation, will ultimately lead to massive and abrupt change on a scale comparable to that seen in previous global extinctions (Nature 473, 133; 2011).

We have failed at the task set at Rio in 1992 for many reasons, not least because of its scale and complexity. Defining sustainability beyond meeting the needs of both present and future generations has proved challenging, and enforcing it even more so. Typically, our environmental policies deal with discrete portions of the Earth system in isolation, failing to recognize how each affects the other. An example, detailed in a Review on page 210 , is the overlooked carbon footprint of the water sector. This problem is more broadly demonstrated by the some 500 international environmental policies of the United Nations - each one having formed in isolation from the next. Even now, major policies such as the Millennium Ecosystem Assessment and the Convention on Biological Diversity are handled separately from our efforts to curb climate change.

Clearly, to achieve sustainability, we need to start with an integrated worldview where the ripple effects of rising greenhouse-gas emissions on biodiversity or of loss of ecosystem resilience on the global economy are considered. This common-sense doctrine has yet to be adopted by international policymakers. Its importance was reiterated recently by a group of Nobel laureates who met in Stockholm this May to carve out a vision of how sustainability could be achieved in reality. Their memorandum reminds world leaders who will gather in Rio in June 2012 that the Earth's physical and biological support systems must be protected together with its socio-economic systems, rather than being treated as opposing forces whose interests are mutually exclusive.

\section{Defining sustainability beyond meeting the needs of both present and future generations has proved challenging, and enforcing it even more so,}

The scientists also called for a research agenda to better understand the limits of global sustainability. This too will require integrated thinking and, importantly, transference of knowledge from fields such as politics and economics to climate science. After all, much of our current efforts in sustainability involve staving off the possibility of pushing the planet past a point where it would shift to a very different state, and one that is not conducive to supporting the well-being of humans or ecosystems. In this regard, much can be learnt from the recent uprisings in the Middle East and from the collapse of the global financial system.

Indeed, research discussed in a Review (page 201) and a Feature (page 180) in this issue shows that a tipping point the crucial moment at which a system transitions to a different state - does not strike entirely by surprise. Far as we are from being able to pinpoint the moment at which tropical forests die off and turn to savannah or bleached corals become overrun with seaweed, recent research suggests that there may be tell-tale signs of impending change. Detecting a change in the Tunisian political system, for example, can have lessons for those seeking to find similar patterns in ecological systems. Evidence from model and palaeoclimate data shows that as a system becomes unstable and moves towards a different state, it becomes less agile and responds sluggishly to disturbance, in what is termed 'critical slowing down'. Similarly, in situ experiments are starting to reveal that elements of ecosystems under stress can become increasingly variable - for example, heavily exploited fish stocks show large fluctuations in population size just before crashing.

What we also now know from research is that stressors have a synergistic effect, and planetary warming in particular seems to narrow the 'safe' range of other stressors, such as the nitrogen load in lakes or fishing pressure in marine ecosystems. Collectively, the effects of multiple agents can add up to an overall loss of the Earth's resilience to humanity's impacts. And once resilience is lost, it can be hard to recover.

The prospect of anticipating abrupt change in key elements of the climate system, from loss of the Amazon to loss of Arctic summer sea-ice is therefore enticing. Recognizing this, the United Nations has called for a global system of early warning systems for all natural hazards. However, successful warning relies on the ability of society to respond to the signals as well on our scientific capability to measure the correct parameters of change and indicators of their approach.

In this regard, the United Nations would do well to realize that such a plan will only work as part of a holistic vision. Next year's Rio 2012 conference will provide a rare opportunity to go back to basics in framing - and in coordinating policy on - global sustainability. This will require no less than a societal tipping point, shifting us from an era of human interference with the Earth to one of planetary stewardship that embraces environmental protection as part of societal and economic protection. Got right, this could ensure that the 'Anthropocene' is very short blip indeed in the vast geological record. 